\title{
Do health care programs addressed to women serve women's needs
}

\author{
Aníbal Faundes* and Laura Miranda \\ Departmet of Obstetrics and Gynecology, State University of Campinas (Unicamp), Brazil
}

\begin{abstract}
Until the last decades of the past century women were included in health care programs only when pregnant, to ensure the birth of a healthy newborn, with contraception to reduce population growth, later as a breast-feeding mother to ensure healthy children development and years later, HIV positive women were given antiretroviral drugs during pregnancy, to prevent transmission of the infection to their babies. It was late in last century that health services dedicated to the care of women themselves were really created, the concept of women's sexual and reproductive health was defined and services to care for women personal needs were developed. Still, in many countries, women's health care is included in Maternal and Child health, showing how women keep being seen mostly as mothers.
\end{abstract}

\section{Introduction}

Historically, during most part of last century, the public health care programs, which in theory were addressed to women health, were limited to "maternal care", which in fact concentrated in the care of the fetus and the newborn and did little to protect women's health and wellbeing, and practically nothing for the health of women who were not pregnant.

When the "population explosion" alarmed the world policy makers, ample resources were allocated to reduce population growth through family planning, which became a main component of "women health care", although the purpose was not women's health, but to reduce the fertility rate, particularly in developing countries.

Sometime later health investigators demonstrated the benefits of breast milk for infant health and development, and stimulation of lactation became a very important element of women's health care, once again with an important purpose, but not the health of the women.

Although important changes have occurred, the basic concepts are still valid as it will be analyzed below.

\section{The purpose of antenatal care}

Until the 1960s, the activities related to women's health were limited to being part of the Maternal and Child care programs. For these programs, the woman existed only as a mother, during pregnancy, labor and the post partum period. More important, the purpose of the care of women during pregnancy, labour and delivery were explicitly addressed to ensure that the newborns were born at term and in full health.

It was only during the last 15 years of the twentieth century that health program started to pay attention to women's health needs. One important milestone was the publication in the prestigious journal, The Lancet, of an article by Allan Rosenfield, a world champion for women's sexual and reproductive health a rights. This important article was an out crying call to pay attention to the abysmal difference between rich and poor women in their risk of dying during pregnancy, the article was titled "Maternal mortality--a neglected tragedy. Where is the $M$ in $M C H$ ?" [1].

The article showed that there was no greater difference in any indicator of socio economic development that that observed in maternal mortality, and while great attention was given to infant mortality, it appears as if the world were indifferent to the unacceptable risk of dying that women in low income countries have to run in the process of giving birth to a new child.

This abysmal different can be illustrated with data from 2016 [2], which shows that while maternal mortality ratio in high-income regions was of 12 per 100.000 live births, the corresponding ratio in Sub-Saharan Africa was of 546 per 100.000 live births. It means that the risk of dying during pregnancy labor and post-partum for a woman living Sub-Saharan Africa was 45.5 folds greater that the risk run by a woman in a rich country.

This message was taken very seriously by the most important organization in the world and from then on, a number of important initiatives were taken to reduce maternal mortality in developing countries.

It doesn't mean, however, than until today, health interventions carried out during antenatal care are addressed exclusively to protect the fetus and the new born and are discontinued after delivery.

During the decade of 1980, the AIDS epidemic became the main health emergency that concentrate the efforts of the world's health authorities. A lot of attention was given to the different forms of contagion, including the so-called, vertical transmission, meaning

${ }^{\star}$ Correspondence to: Anibal Faundes, P.O. Box 6181, CEP 13083-970 Campinas, São Paulo, Brazil. Phone: 55-19-3289-2856; E-mail: afaundes@uol. com.br

Key words: maternal and child health, sexual and reproductive health, antenatal care, family planning, breastfeeding

Received: July 10, 2018; Accepted: July 16, 2018; Published: July 23, 2018 
the transmission from a HIV infected mother to her newborn. That form of transmission led the health authorities to impose the HIV test to all pregnant women. Those pregnant women who were confirmed as HIV positive, were given Antiretroviral therapy (ART) during pregnancy, which was terminated by cesarean section, to prevent the HIV transmission to the newborn child.

For a long time, in many circumstances, the ART treatment was discontinued after birth, as a clear demonstration that this health support given during pregnancy and the surgical termination of pregnancy by C-Section have the only purpose of protecting the newborn and not the woman.

Women's care in these situations were clearly addressed to the care of the newborn and not of the woman, who had to accept the risk of a C-section for the sake of the newborn and received ART drugs only for their babies but not for them.

This situation may have changed later, but similar behavior is observed until now and even in developed countries. For example, efforts are made to prevent alcohol consumption "during pregnancy" to prevent damage to the fetus and the newborn [3], but that effort last only until the baby is born, in spite of the consequences of alcohol, consumption for women's health [4].

\section{Family planning programs}

During the decade of 1960 , the "population explosion" became a main for alarm among politicians in high income countries. They decided that it was necessary to act in order to reduce the high rate of population growth in low and inter-median income countries. Large resources were dedicated to preventing excessively rapid population growth through family planning programs.

Women were motivated and sometime, imposed to use contraceptive methods to prevent pregnancies, but once again, the purpose of the well-funded family planning programs was not to protect women's health, but to reduce population growth. Moreover, they were inducing to accept surgical sterilization or IUD insertion by paying to the women themselves or worse, to the providers who induce the "acceptance" of these methods by their clients [5].

Even worse was the case of massive program of surgical sterilization without the women's consent, which became public in Peru, and lead to legal accusation against President Fujimori [6].

\section{Promotion of breast feeding}

During the decade of 1970 investigators found that mothers' breast milk could not be replaced by artificial milk formulas. The benefits of breastfeeding starts with the consolidation of the psychological motherchild attachment, followed by the reduction of neonatal morbidity and mortality through the transmission of immunoglobulin, changes in the gastrointestinal bacteria of the baby and preventing the exposure to pathogens in the water and other milks [7].

For those reasons, governmental health programs were developed to promote breast feeding. Women were stimulated to breastfeed their babies for at least six months after birth and a lot of attention was given to women to achieve that purpose. But once again the purpose was not to promote women' health, but the health of their babies, although breastfeeding at an early age and prolong breastfeeding are protective factors against breast cancer.

The problem is that some breast-feeding programs could become an "unfriendly imposition", which could lead to post-partum distress for women who have severe difficulties to breastfeed [8-9].
Thus, once again, a health program addressed to women did not give do consideration to women health but use women as a means to achieve another important health purpose.

In summary, the objective of antenatal care was to get a healthy newborn, the objective of family planning services was to reduce population growth, the objective of promoting breast feeding was to ensure child health. All these health programs addressed to women did not have the objective of protecting women's health, but other socially important objectives. Such health programs simply used the women as a means to achieve their purposes.

\section{Recognition of women's sexual and reproductive rights and evolution of women's health programs}

It was only at the International Conference on Population and Development (ICPD) held in Cairo in 1994, for the first time recognized women's sexual and reproductive rights [10]. The ICPD Programme of Action, item 7.2, states that Reproductive and Sexual Health means that people could have a satisfactory and safe sexual life, that women have the capacity to have children and to decide if they wish to have a child, when and how often. It also means that men and women have the right to be informed and have access to effective, accessible and acceptable family planning methods, as well as to other methods of fertility regulation of their choice, which are not against the law. This Program of action was ratified by more than 120 countries around the world.

In other words, at the ICPD, the international community defined and promoted women's reproductive and sexual rights and health as never before, moving from programs limited to provision of family planning methods and services toward a broader vision of providing women's reproductive and sexual care attending their broader needs for health services.

The ICPD acknowledged individuals' right to access to reproductive health information and reinforced the link between women's reproductive health and gender power equity.

The evolution of the care for women's sexual and reproductive health during the last two decades, however, has not been as positive as expected. By the end of the twentieth century the population explosion was already under control in most of the world and the motivation to provide resources for family planning almost disappeared. The AIDS epidemic became priority and received increasing resources, leaving women's sexual and reproductive rights far behind in the distribution of financial support.

In the field of reproductive and sexual health, only maternal mortality remains as a priority and was given great attention. Women's need for family planning services received far less attention and not sufficient resources remained available to cover the provision of contraceptive methods to the women in need in less developed countries.

While the priority of reducing maternal mortality cannot be discussed, we can argue for the relevance of fulfilling the women's contraceptive needs in order to achieve that purpose.

If we look at the main causes of maternal mortality, hypertension in pregnancy, post-partum hemorrhage and unsafe abortion, and review the interventions which has shown to be effective to reduce them, we will realize that contraception plays a very important role.

Contraception has the potential to reduce the risk of maternal death by preventing the pregnancy of women with higher risk of dying 
during pregnancy, labour and in the post-partum period in the country where maternal mortality ratio is highest. Women with higher risk of maternal death are those with chronic conditions, like hypertension, diabetes, severe anemia, cardiac dysfunctions, and also those who have already have obstetrics complications, such retained placenta, placenta previa, hypertension in pregnancy, for example.

All those conditions can be identified during delivery and postpartum care, giving to the health provider the opportunity to educate and motivate the women and her family about the risk those women run in the next pregnancy, offering highly effective contraceptive methods and providing such methods before discharge.

Similarly, the provision of family planning counseling and administration of highly effective contraception, immediately after abortion, has shown its effectiveness in reducing induced abortion, which is a main cause of maternal mortality in less developed countries where abortion is usually illegal, and consequently unsafe [11].

In spite of all that, not enough progress has been made in reducing unmet need of contraceptive in developing countries. Some progress has been, in fact, achieved in improving access to safe abortion services within the law and in moving toward less restrictive abortion laws [12-13].

The ineffectiveness of restrictive abortion law to reduce its rate and its tragic consequences over the health of the women of low economic resources is increasingly being recognized and positive legal changes have occurred in a number of developing countries such as Nepal, Uruguay, Bolivia and Malawi, during the last few years.

We are far behind, however in other aspect of the protection of women reproductive health. Education, information and the means for prevention of sexually transmitted diseases (STD), starting an early age, should also be provided and for both sexes, but it is currently missing particularly in low resource setting where it is most needed.

In summary, women's sexual and reproductive rights and health needs were practically ignored until the final decades of last century and it was finally recognized before the end of the twentieth century.

The practical provision of the key health care interventions that respond to women's sexual and reproductive needs is, however, still far behind women's needs in developing countries.

\section{Conflicts of interest}

The authors have no conflicts of interest to declare.

\section{References}

1. Rosenfield A, Maine D (1985) Maternal mortality--a neglected tragedy. Where is the M in $\mathrm{MCH}$ ? Lancet 2: 83-85. [Crossref]

2. Alkema L, Chou D, Hogan D, Zhang S, Moller AB, et al. (2016 ) Global, regional, and national levels and trends in maternal mortality between 1990 and 2015, with scenario-based projections to 2030: a systematic analysis by the UN Maternal Mortality Estimation Inter-Agency Group. Lancet. 387:462-74. [Crossref]

3. Doi L, Cheyne H, Jepson R (2014) Alcohol brief interventions in Scottish antenatal care: a qualitative study of midwives' attitudes and practices. BMC Pregnancy Childbirth. 14:170. [Crossref]

4. McKnight-Eily LR, Henley SJ, Green PP, Odom EC, Hungerford DW (2017) Alcohol Screening and Brief Intervention: A Potential Role in Cancer Prevention for Young Adults. Am J Prev Med 53: S55-55S62. [Crossref]

5. Ross JA, Isaacs SL (1988) Costs, payments, and incentives in family planning programs: a review for developing countries. Stud Fam Plann 19: 270-283. [Crossref]

6. Málaga G (2013) [Forced sterilizations, reproductive rights and informed consent]. Rev Peru Med Exp Salud Publica 30: 521-522. [Crossref]

7. Van der Wijden C, Kleinen J. Lactational amenorrhea for family planninh. Cochrane database Syst. Rev. 2003:CD001329.

8. Schmied V, Thomson G, Byrom A, Burns E, Sheehan A, et al. (2014) A metaethnographic study of health care staff perceptions of the WHO/UNICEF Baby Friendly Health Initiative. Women Birth 27: 242-249. [Crossref]

9. Palmér L, Carlsson G, Brunt D, Nyström M (2014) Existential vulnerability can be evoked by severe difficulties with initial breastfeeding: a lifeworld hermeneutical single case study for research on complex breastfeeding phenomena. Breastfeed Rev. 22:2132. [Crossref]

10. United Nations. Report on the International Conference on Population and Development, Cairo, 5-13 September 1994. Programme of Action. Available at: ttp:// www.un.org/popin/icpd/conference/offeng/poa.html.

11. Johnson BR, Ndhlovu S, Farr SL, and Chipato T (2002) Reducing unplanned pregnancies and abortion in Zimbabwe through post-abortion contraception. Studies in Family Planning. 33: 195-202.

12. Faúndes A1, Rao K, Briozzo L (2009) Right to protection from unsafe abortion and postabortion care. Int J Gynaecol Obstet 106: 164-167. [Crossref]

13. Shah IH, Åhman E, Ortayli N (2014) Access to safe abortion: progress and challenges since the 1994 International Conference on Population and Development (ICPD). Contraception 90: S39-48. [Crossref]

Copyright: (C2018 Faundes A. This is an open-access article distributed under the terms of the Creative Commons Attribution License, which permits unrestricted use, distribution, and reproduction in any medium, provided the original author and source are credited. 